\title{
Tirando as máscaras: 0 reality show e a busca pela autenticidade no mundo contemporâneo
}

\section{Bruno Campanella}

\section{Resumo}

0 artigo busca refletir sobre a importância do conceito de autenticidade para a audiência do reality show Big Brother Brasil (BBB).

Os resultados da etnografia midiática de uma comunidade on-line de fãs do programa sugerem que as condições criadas pelo confinamento da casa do BBB seriam as ideais para a revelação da autenticidade dos participantes do reality show. 0 ponto de partida da reflexão apresentada neste trabalho tem como referência fundamental a análise do modelo romântico de "self expressivo", ainda em voga no ocidente. Segundo esse paradigma, todo indivíduo tem uma autenticidade própria que, supostamente, pode ser suprimida por "máscaras sociais" adotadas. Para os fãs do BBB, contudo, certos aspectos do confinamento dos participantes do programa seriam capazes de forçar a retirada dessas máscaras.

\section{Palavras-Chave}

Big Brother Brasil. Subjetividade.

Confinamento. Autenticidade.
Bruno Campanella I Email: brunocampanella@yahoo.com Doutor em Comunicação e Cultura pela Universidade Federal do Rio de Janeiro (UFRJ) e mestre em Comunicação Transnacional e Mídia Global pelo Goldsmiths College, University of London. Professor do Departamento de Estudos Culturais e Mídia da Universidade Federal Fluminense (UFF) e do Programa de Pós-Graduação em Comunicação (PPGCOM) da UFF.

\section{Introdução}

Este trabalho propõe uma reflexão acerca da importância do conceito de autenticidade para a audiência de reality shows, em particular, do Big Brother Brasil (BBB). A partir de uma etnografia midiática ${ }^{1}$ feita com membros de uma comunidade on-line de fãs do BBB foi possível constatar que a capacidade dos participantes do programa de se apresentarem como "indivíduos autênticos" é vista como fundamental para que tenham sucesso ao longo da disputa pelo prêmio oferecido pela produtora do reality show no Brasil. Embora 0 formato em questão claramente se proponha a ser um jogo, com uma estrutura que favorece a adoção de estratégias e alianças por parte dos competidores, a audiência analisada não percebe com bons olhos a construção de "tipos" ou de personas que visem galvanizar a simpatia de colegas e de membros do público a partir de máscaras que encubram seus selves "verdadeiros". Em vez disso, os fãs do BBB parecem advogar em prol de um modelo de sujeito que deve ser fiel a uma suposta interioridade original (uma autenticidade), que precisa ser respeitada a todo custo. 
Para entender as origens e implicações desse fenômeno é necessário, contudo, analisar como se constituiu historicamente alguns aspectos da "topografia moral" que regula a concepção contemporânea de self no ocidente. A partir desta análise, será possível entender como as condições apresentadas pelo confinamento dos participantes do Big Brother Brasil - caracterizado pelo isolamento da família e do mundo cotidiano fora da casa, pela necessidade de constante participação em provas de resistência, pelo dia a dia permanentemente vigiado por câmeras, entre outros aspectos - são consideradas pelos fãs do formato como ideias para a revelação da autenticidade dos competidores. Em outras palavras, este artigo busca refletir acerca da crença de que a casa do BBB é o lugar perfeito para que as máscaras sociais utilizadas pelo indivíduo comum participante do reality show sejam expostas.

\section{A autenticidade como le sentiment de l'existence}

Charles Taylor (1997) sugere que a ética da autenticidade que guia 0 self contemporâneo nasceu na segunda metade do século XVIII período de surgimento do romantismo europeu - quando é possível identificar o aparecimento de uma crescente valorização dos laços comunitários e de uma crítica direcionada à "racionalidade desengajada" do iluminismo (TAYLOR, 1997, p. 25). No campo da literatura, o romantismo inaugurou um tipo de escrita caracterizado pela ênfase dada às experiências de um "eu interior", muitas vezes encontrado no gênero dos diários confessionais e das cartas pessoais. Essa nova interioridade pessoal passa a ser vista como 0 lócus de uma suposta originalidade latente em cada indivíduo. Consequentemente, para alcançar uma existência verdadeira e construtiva, o sujeito deve respeitar a sua voz interior - em outras palavras, ser autêntico.

A ética da autenticidade substituiu uma anterior, na qual os conceitos de certo e errado estavam vinculados a uma preocupação com recompensas e punições divinas. A fonte moral para as decisões estavam em Deus, ou numa "ideia de bem", ambas localizadas externamente ao indivíduo. Taylor (1997, p. 26) lembra que Santo Agostinho já propunha a existência de uma interioridade no indivíduo, porém uma na qual a referência moral não era intrínseca a ele, mas localizada na esfera do divino.

De acordo com Taylor (1997), Rousseau e Herder teriam sido os principais porta-vozes da mudança nessa tradicional visão teística da subjetividade humana. As pressões impostas pelo mundo exterior, por outras pessoas, enfim, pela sociedade

As análises apresentadas neste artigo são informadas por uma etnografia midiática realizada no ano de 2008, constituída pela observação participante da comunidade de fãs do programa e por entrevistas presenciais com seus membros (foram quatro meses de observação e 15 entrevistas presenciais no total). Maiores detalhes metodológicos desta pesquisa podem ser encontrados em Campanella (2012, p. 36-44). 
de um modo geral, representam, segundo essa nova moral, ameaças à única voz que 0 indivíduo realmente deve escutar, àquela que lhe confere autenticidade: a sua voz interior.

\section{A inautenticidade da sociedade}

Lionel Trilling (1972, p. 141) alega que, concomitantemente ao surgimento do sujeito autêntico (o que é fiel à sua natureza interior), iniciou-se na Europa o que 0 acadêmico americano chama de "onda do desmascaramento". 0 autor propõe que as pesquisas desenvolvidas por Sigmund Freud acerca dos modos de trabalho do sistema do inconsciente devem ser inseridas dentro desse contexto. Segundo Freud, o homem teria desenvolvido mecanismos de repressão de seus instintos libidinosos - estes considerados autênticos - para que a vida em sociedade se tornasse possível. A neurose, presente em todo ser humano, de acordo com o psicanalista, seria, portanto, um produto desse processo de repressão. Ela é a maneira encontrada para lidar com os "simbolismos desviantes" resultantes da relação complexa entre 0 ego e o id (FREUD 1963 apud TRILLING, 1972, p. 142-143). Implicitamente, Freud (1963) está sugerindo que a vida mental neurótica do homem - sempre presente, em maior ou menor grau o torna naturalmente inautêntico. Ou seja, a construção da vida em sociedade, necessária para sobrevivência do ser humano, é responsável por uma patologia universal que impede 0 acesso do indivíduo ao seu verdadeiro eu.
Colocada sob essa perspectiva, a prática da psicanálise operaria como uma tentativa de autoconhecimento. Isto é, como um exercício de interpretação do intricado embate entre 0 consciente e 0 inconsciente, em última análise, como uma busca pela autenticidade do indivíduo.

Ainda de acordo com a descrição que Trilling faz das ideias de Freud, o superego é o instrumento por meio do qual a sociedade exerce sua coerção externa sobre o homem. Esse processo tem início na infância, quando a criança começa a se transformar em um ser moral e social, ao internalizar as normas vigentes de comportamento e os tabus, ao mesmo tempo em que abre mão do seu desejo libidinal. Tendo o superego como elemento transformador, o homem "deixa de se opor à civilização para se tornar o seu veículo", por meio de um processo de sublimação (TRILLING, 1972, p. 153).

Em diálogo com as ideias de Freud, Herbert Marcuse sugere que o desenvolvimento tecnológico liberta 0 ser humano da luta pela sobrevivência. Como consequência, o superego, culturalmente desenvolvido pelo homem, segundo o filósofo, é relaxado. 0 problema é que esse processo estaria sendo acompanhado por uma simultânea mudança no papel tradicional da família. Esta, classicamente responsável pela formação do superego, tem, na modernidade, a sua atuação reduzida. As disputas e castrações impostas à criança, fundamentais para que ela desenvolva impulsos e ideias próprias, não 
acontecem com o mesmo vigor. 0 processo de individuação resultante da imposição da autoridade da família, especialmente do pai, corre riscos nesse novo cenário (MARCUSE, 2005, p. 95). Como resultado, Marcuse sugere que esse novo sujeito que não precisa mais lutar pelo seu espaço, que não herda o complexo de Édipo e que vive em uma sociedade hedonista, seria mais facilmente manipulável. 0 processo de individuação, responsável pela formação de sua capacidade de resistência às forças exteriores e, por conseguinte, pela sua autenticidade, estaria se perdendo.

Mesmo que Marcuse veja o superego como a fonte de autenticidade do indivíduo, e Freud como a de inautenticidade, ambos são exemplos de pensadores que, assim como vários outros no século XX, percebem a sociedade como sendo essencialmente inautêntica.

\section{A segurança ontológica do sujeito sob risco}

Giddens (1991) e Beck (2001) sustentam que a atual sociedade de risco exerce um tipo de pressão sobre 0 indivíduo que pode ameaçar a sua própria segurança ontológica, criada nos primeiros estágios de seu desenvolvimento. Quer dizer, esse indivíduo deixa de ter garantidas questões existenciais fundamentais para que possa manter um sentido de self.

Winnicott (1988) descreve o período inicial de formação do sujeito como fundamental para que ele desenvolva essa relação de confiança com o mundo externo. Sobretudo a mãe, segundo Winnicott, deve prover as condições para que a criança forme uma segurança ontológica, que servirá de base para a sedimentação de uma atitude de espontaneidade perante 0 mundo. 0 psicanalista britânico alega que o ser imaturo "está continuamente a pique de sofrer uma ansiedade inimaginável" (WINNICOTT, 1988, p. 56, grifo do autor). Esse ser é constantemente chamado à existência pelo ambiente onde é criado. Por esse motivo, a mutualidade entre a pessoa que toma conta e a criança é uma sociabilidade fundamental que precede a diferenciação do sujeito entre 0 "eu" e 0 "não eu".

Giddens, em uma reflexão sobre a questão da segurança ontológica do sujeito, afirma que a realidade da criança começa a ser entendida como um conjunto de experiências entre ela e os pais. A certeza de que estes sempre voltarão ajuda a solidificar no ser imaturo uma "confiança básica, que forma o nexo original do qual emerge uma orientação emotivo-cognitiva aos outros, ao mundo-objeto e à identidade do eu" (GIDDENS, 1991, p. 38). Conforme o sujeito se desenvolve, a sua segurança ontológica passa a ser protegida por meio das rotinas diárias do cotidiano, o que o mantém afastado de possíveis ansiedades existenciais. Dentro desse contexto, é possível interpretar a descrição que Goffman (1983) faz dos diferentes modos de a pessoa apresentar o seu "eu" (self) na vida cotidiana como uma estratégia de preservação da sua segurança ontológica. Em 
última instância, o que importa para o sujeito, segundo Goffman (1983, p. 231), é ser acreditado pelo mundo exterior. Ter a aparência e a atitude aceitas pelos outros como normais significa que 0 seu sentido de self não está correndo perigo, isto é, que o sujeito não é chamado a refletir sobre a sua relação com 0 seu próprio corpo.

Uma das questões crucias trazidas pelas ideias de Goffman acerca do comportamento do ser humano diz respeito ao fato de que 0 cotidiano deste é sempre cercado por convenções sociais, independentemente da época ou da cultura em que vive. Qualquer tipo de emoção que uma pessoa sinta, mesmo as mais fortes e sinceras, é manifestada de acordo com as regras e convenções definidas em sua própria sociedade, para que sejam compreendidas corretamente (ERIKSEN, 2001, p. 52). Assim como Goffman, tanto Laing quanto Winnicott buscam desenvolver uma perspectiva do self que se aplique a indivíduos independentemente de seus contextos sócio-históricos. A formação da segurança ontológica do self, descrita pelos dois últimos, ocorreria em um período "pré-cultural" da criança, quando esta ainda estaria criando uma relação com o mundo exterior.

Laing sustenta, no entanto, que essa segurança ontológica pode correr riscos sempre que 0 sujeito - predisposto - se encontrar em situações em que ocorra uma grande ruptura entre as rotinas vivenciadas por ele e a sua narrativa biográfica individual. Ou seja, nos momentos em que acontecimentos do mundo exterior lhe pareçam de tal modo fora de lugar, que 0 sujeito é obrigado a agir como se estivesse em uma atuação permanente; ele perde 0 seu sentido de identidade pessoal. Esse processo seria desencadeado, de acordo com Laing, em situações de grande tensão e estresse dentro do cotidiano desse sujeito. Como resultado, os eventos que o cercam começariam a lhe parecer falsos. A pessoa passa a ter uma sensação de descorporalização, na qual sente que o corpo é manipulado pelo seu self por trás dos bastidores, isto é, ela começa a refletir sobre o seu corpo como se não estivesse dentro dele (LAING, 1973, p. 179).

Em um mundo no qual garantias estabelecidas pela tradição deixam de existir, o indivíduo deve agora ser 0 único responsável pelas suas escolhas; ele precisa buscar na sua interioridade as respostas para as dúvidas que se apresentam no dia a dia. A sua identidade pessoal precisa ser atualizada permanentemente por meio do consumo de estilos de vida. Beck argumenta que "na segunda modernidade, a estrutura da comunidade, grupo e identidade perde esse cimento ontológico" (BECK, 2001, p. 10).

Dentro de um novo cenário de incertezas e múltiplas escolhas, no qual o cotidiano está em constante mutação, o sentido de identidade pessoal torna-se instável. A segurança ontológica do indivíduo - formada na sua primeira infância sofre constastes ameaças do mundo exterior. "No projeto reflexivo do self, a narrativa da identidade 
pessoal é inerentemente frágil”, afiança Giddens (1991, p. 185). Em casos extremos de ansiedade e tensão, 0 indivíduo pode perder o sentimento de continuidade biográfica, ele começa a se sentir desprotegido, quebrando a "confiança básica" no mundo exterior que fundamenta a sua segurança ontológica.

\section{0 cotidiano do BBB: buscando a autenticidade do indivíduo}

As dificuldades impostas aos participantes de reality shows, contudo, raramente são articuladas pela audiência sob o enfoque da ameaça à segurança do sujeito. 0s resultados de uma etnografia midiática de uma comunidade on-line de fãs do Big Brother Brasil conduzida durante as exibições programa nos anos de 2008 e 2009 revelam que muitos fãs do BBB acreditam que a pressão imposta aos confinados é fundamental para que se possa obter a autenticidade deles. As características relacionadas ao jogo, em especial, parecem ser as mais eficientes nesse aspecto. De um modo mais concreto, esses membros da audiência creem que as constantes provas de resistência - tanto físicas quanto emocionais - associadas ao isolamento do mundo exterior criam as condições ideais para se conhecer as personalidades autênticas dos participantes. Tais circunstâncias são potencializadas pelo confinamento de pessoas que são, inicialmente, desconhecidas entre si, em um ambiente projetado para aumentar a sensação de desorientação espaço/temporal e desconforto, além da constante apresentação para diferentes audiências. Em outras palavras, ao invés das condições adversas criadas pela produção do BBB induzirem o confinado a um possível breakdown psicológico, que ameace a sua segurança ontológica, espera-se que elas façam ele ser verdadeiro com ele mesmo e com a audiência.

Material Girl, por exemplo, está convencida que o diretor do Big Brother no Brasil, o José Bonifácio Brasil de Oliveira (popularmente conhecido pela alcunha de Boninho), deveria ter feito os participantes do BBB8 sofrerem ainda mais para que fosse possível "quebrar as cascas" (ou máscaras) que, supostamente, estes estariam usando para esconder seus "eus" verdadeiros.

0 que me assusta nesse grupo [participantes do BBB8] é que eles estão conseguindo 'segurar a onda'ao máximo. E as coisas devem piorar muito, porque quando o Boninho fica puto... os castigos, entendeu? Eu ainda não entendi porque não teve um acorrentado. Acorrentado de verdade, com corrente, como teve no quatro [BBB4]. Que foi um negócio complicado. Porque que não teve uma gaiola ainda? Aquilo foi extremamente cruel, aquela prova do Alemão [referindo-se a uma prova do BBB7 em que os confinados dividiam uma gaiola minúscula, na qual tinham que ficar em pé, sem que pudessem comer, beber ou ir ao banheiro, e que teve como vencedor um participante que resistiu por quase 22 horas]. Aquilo foi... Eu estou desde a primeira semana, que estou gritando lá no fórum [BBB. Lua]: gaiola neles, gaiola neles! Porque é um povo que merece sofrer um pouco, mais para 
ver se as resistências caem, e você descobre quem está por trás daquelas cascas, entendeu? Porque eles são muito "casca-grossa", eles são muito preparados. ${ }^{2}$

É interessante notar o sentimento ambíguo demonstrado por Material Girl acerca do sofrimento dos confinados. Se, por um lado, ela manifesta ciência da crueldade infligida por algumas provas, por outro, a fã exprime simpatia pelo uso deste recurso quando ele se fizer "necessário". 0 que, para a comentarista, aconteceria quando fosse preciso punir os participantes por não se mostrarem por completo ou para, justamente, obrigá-los a fazê-lo. Vários fãs se queixavam durante as primeiras semanas do BBB8 que os participantes daquela edição não queriam se expor no programa. De acordo com essa perspectiva, $o$ fato de os confinados terem mantido uma convivência harmoniosa naquele período, sem intrigas ou qualquer sinal de desavença maior, significava que eles não estavam sendo fiéis às suas personalidades verdadeiras.

Para os fãs, essa inautenticidade consciente dos participantes do BBB seria alcançada por meio de uma capacidade desenvolvida por estes de reprimir seus impulsos originais.

Assim como Material Girl e muitos outros fãs, a blogueira Susan também mostrava preocupação com o grau de "preparação" dos confinados daquela edição do reality show. Ela deixou essa posição clara em nossa entrevista, quando afirmou que: "Esse até [refere-se ao BBB8], eu fiquei meio preocupada. Achei que o programa fosse custar a decolar. Porque essa turma que está lá é muito resistente à pressão, não é?”3 Aproximadamente um mês após a entrevista, quando 0 ambiente de aparente harmonia na casa já havia se transformado, Susan comentou em seu blog sobre a importância das intervenções da produção do Big Brother no sentido de aumentar a pressão para que as "máscaras caíssem". Somente dessa maneira, acredita a blogueira, foi possível conhecer os confinados de verdade. No post em que escreveu sobre o assunto, Susan declarou que:

Quase todos criticaram as máscaras dos jogadores dessa edição do Big Brother Brasil, nós aqui na net, a mídia especializada, (sic) era tão grande a negativa desse grupo de se envolver na realidade que eles viviam, que a direção do programa precisou intervir com novidades para sacudir o coreto e fazer com que os jogadores levantassem a bunda da piscina e começassem a mostrar quem eles realmente eram. ${ }^{4}$

A perspectiva de que situações limites de estresse podem fazer com que as pessoas "mostrem quem elas realmente são" não é exclusiva dos fãs do Big Brother Brasil. No trabalho em que explora os significados adquiridos pela franquia televisiva $S o$ You Think You Can Dance (SYTYCD) em diferentes países, Dana Heller (2009) alega que a estrutura do

Entrevista concedida para esta pesquisa em 20 de fevereiro de 2008.

Entrevista concedida para esta pesquisa em 12 de fevereiro de 2008.

Trecho de post publicado por Susan no blog De Cara Pra Lua <http://decarapralua.zip.net/> em 10 de março de 2008. 
programa privilegia a comunicação de uma suposta autenticidade dos participantes. SYTYCD é um reality show de competição de dança em que casais devem se apresentar para uma plateia e um grupo de jurados ao longo de várias semanas. Durante 0 período de produção do programa, a audiência pode acompanhar pela TV o processo de preparação das coreografias, as dificuldades encontradas pelos casais, assim como a evolução de suas técnicas e do seu entrosamento. A dupla vencedora é aquela que sobrevive ao processo semanal de eliminação. A qualidade artística dos competidores seria, de acordo com Heller, somente um entre vários aspectos levados em conta pelo público no momento da escolha dos seus preferidos. Segundo a autora, a autenticidade demonstrada pelas duplas ao longo das semanas também seria um fator importante para que elas sejam bem sucedidas na competição. Na versão norte-americana, por exemplo, essa característica se materializaria pela frequente perda de controle emocional dos participantes (e também dos jurados) diante do público. A pressão decorrente do treinamento intensivo, da obrigação de se apresentar de maneira adequada em frente às câmeras e da necessidade de sobreviver às eliminações constantes criariam as condições ideais - segundo convicção tanto da produção como da audiência - para que a autenticidade dos indivíduos que participam do reality show seja transmitida (HELLER, 2009, p. 132-133).

Assim como Heller, Andrejevic (2002) também propõe a existência de uma percepção comum na sociedade contemporânea, segundo a qual, a sujeição do indivíduo a uma situação de pressão extrema pode trazer sua autenticidade à superfície. $0 u$ seja, acredita-se que nos momentos em que dada pessoa está determinada a usar uma máscara social, agindo, portanto, de maneira insincera com o seu eu interior, deve-se deslocá-la de sua segurança cotidiana para que seja possível ganhar novamente acesso ao seu "verdadeiro eu". Em um primeiro momento, pode-se pensar que essa crença seja contrária aos estudos de Laing (1973). Para o psiquiatra britânico, a quebra da segurança ontológica do sujeito leva a algum tipo de doença psíquica, como a esquizofrenia. Contudo, para uma parcela da população, incluindo os fãs do BBB citados anteriormente, essa mesma situação limite produziria algo positivo e desejável: a autenticidade do indivíduo. Uma análise mais detalhada da questão, entretanto, mostra que talvez exista de fato uma relação entre essas duas possibilidades dentro do imaginário da sociedade atual. Quer dizer, as pessoas não pensariam haver uma contradição em relacionar algumas doenças psíquicas com autenticidade. As investigações realizadas por Lionel Trilling (1972) e Anthony Giddens (1991) podem oferecer algumas pistas promissoras no sentido de desvendar essa ligação.

Giddens, por exemplo, descreve a contemporaneidade como um mundo de incertezas no qual o cotidiano pessoal está em constante transformação. Uma das consequências mais dramáticas dessa ameaça ao indivíduo é a quebra de sua segurança ontológica. Nesse cenário, a esquizofrenia estudada por Laing (1973) passa a ser vista como uma patologia cada vez mais comum na atualidade. Em sintonia com 0 
quadro apresentado por Giddens e Laing, Trilling apresenta estimativas indicando que uma em cada 100 crianças nascidas nos dias de hoje desenvolve, em algum momento de suas vidas, a condição mental esquizofrênica (TRILLING, 1972, p. 168). 0 autor prossegue, afirmando que o insucesso de se estabelecer as causas da esquizofrenia em fatores biológicos levou os pesquisadores à buscar em componentes sociais as origens da disfunção em questão. Na base dessa proposição, existe um entendimento de que a sociedade - percebida como lócus de inautenticidade por pensadores como Freud e Marcuse - seria o berço desses componentes.

Trilling (1972) sugere, entretanto, que a relação sociedade $<=>$ inautenticidade gerou a estranha noção de que autenticidade e insanidade poderiam ser igualmente conectados. A correspondência descrita pelo autor estaria fundamentada em duas premissas básicas. A primeira diz respeito à visão de que a insanidade seria uma resposta do indivíduo que quer se libertar da natureza opressora da sociedade. No mínimo, essa condição mental pode ser, nesse caso, interpretada como uma crítica à sociedade. A segunda premissa refere-se à perspectiva de que a insanidade é uma recusa a circunstâncias demarcadoras de um modo geral, sinalizando um modo de existência autossuficiente garantidor do seu próprio poder.

No livro Madness is Civilization, Richard Staub argumenta que, especialmente na década de 1960, várias teorias surgiram tentando descrever a insanidade como uma rejeição às regras de conduta estabelecidas dentro da sociedade ocidental moderna (STAUB, 2011). Trilling, no entanto, questiona a noção de que seja razoável relacionar insanidade com autenticidade. Trilling (1972, p. 171) explica sua posição no trecho abaixo:

Mas aquele que já tenha falado, ou tentado falar, com um amigo psicótico vai admitir trair a dor camuflada de sua confusão e solidão, ao torná-la o paradigma da libertação das falsidades aprisionadoras de uma realidade social alienada? [...] Contudo, a doutrina de que loucura é saúde, de que loucura é liberação e autenticidade, recebe alegremente as boas-vindas de uma parte razoável da população educada.

A despeito de argumentos contrários, grande parte dos membros da Net.BBB - conforme a comunidade de fãs é conhecida por seus participantes mais antigos - não rejeita a ideia de que todo indivíduo possui uma autenticidade que pode (e deve) ser desvendada quando este é submetido a um intenso estresse psicológico. Houve, inclusive, um competidor do Big Brother Brasil oito que decidiu fazer da busca pela autenticidade alheia o seu objetivo maior naquela edição do reality show.

\section{Dr. Marcelo, 0 tirador de máscaras do BBB8}

Depois de uma participação relativamente inexpressiva nas primeiras semanas, Marcelo, um médico de Uberaba, estabeleceu como meta 
central de sua estadia na casa "tirar as máscaras" dos seus companheiros de Big Brother.

Conhecido na Net.BBB por vários apelidos, entre eles psicodoido, psicopata, doutor, psicogay ${ }^{5} \mathrm{e}$ marcelouco, o mineiro começou gradativamente a desafiar as posturas dos seus colegas de confinamento, os quais considerava inautênticos. Após pouco mais de um mês do início daquela edição, Marcelo escreveu sobre suas intenções no Blog dos Participantes mantido pela produção. Diariamente, os confinados eram convidados a escrever algumas linhas sobre suas vidas dentro da casa, em um blog pessoal acessado por um computador localizado no "confessionário". Embora os competidores pudessem escrever nesse blog toda manhã, eles não tinham qualquer tipo de acesso à eventuais comentários de internautas, aos blogs de seus parceiros, ou qualquer outro meio de trocar informações com 0 exterior. 0 médico, porém, ao invés de simplesmente descrever seu cotidiano, ou mandar mensagens para amigos, familiares ou fãs, o que era tradicionalmente feito pelos outros confinados, iniciou um conto, escrito em vários capítulos, com personagens inspirados nos integrantes daquela edição do reality show (que, contudo, eram referidos por meio de nomes fictícios). Em um desses relatos, Marcelo - rebatizado de Gregório em sua novela semificcional - proclama a nova estratégia a ser adotada junto aos parceiros:
GREGÓRIO RODRIGUES DE LYRA SOUTO - Depois de ter sua vida exposta ao mundo, resolve partir em uma busca implacável pela VERDADE de cada um com quem convive, nem que isso gere conflitos quase impossíveis de administrar - mas não para ele. ${ }^{6}$

0 médico acreditava ter ganho legitimidade para "tirar as máscaras" de seus parceiros de confinamento ao ter confessado em público sua homossexualidade, o que, segundo ele, seria o segredo mais importante de sua vida. Em diversas situações, Marcelo mostrou-se decidido a questionar seus colegas de confinamento quanto às supostas tentativas de estes esconderem suas "verdadeiras faces". Comentando sobre uma discussão que teve em uma festa com o roqueiro emo Rafinha, o uberabense escreveu o seguinte comentário em seu blog:

\section{Gregório provou a Cascatinha [nome fictício dado à Rafinha por Marcelo em seu conto] que não é necessário 'agressão física ou verbal' para arrancar máscaras. \\ Ele fez Cascatinha tirar sua própria máscara numa certa festa, sem que soubesse o que estava fazendo..rs" (cont.) ${ }^{7}$}

Embora não excluísse nenhum participante de sua busca, Marcelo mostrava-se particularmente incomodado com Thatiana, uma professora de inglês com quem teve vários desentendimentos na casa. Em um deles, o médico não conseguiu se conter, após entreouvir, por acaso, uma conversa em que Thatiana alegava que somente Juliana 
(sua melhor amiga no reality show), Marcos (seu namorado de confinamento) e ela própria seriam autênticos. Marcelo imediatamente interpelou a professora, iniciando o seguinte diálogo:

Marcelo: Desculpe, assim, me intrometer [...] mas eu estava lá fora e ouvi algumas coisas. Sabe Thati, tem certos momentos em que a gente tem que se preocupar mais com a gente mesmo, com o que a gente é, do que com os outros. Porque se a gente for fazer tudo em função dos outros, a gente não faz aquilo que a gente tem que fazer em função da gente mesmo. E a gente perde uma coisa que se chama autenticidade. É... sinceramente!

Thatiana: Que bom você ter falado isso... [Marcelo interrompe Thatiana e prossegue]

Marcelo: Sabe... a gente está num jogo, e aqui, uma coisa que a gente tem que ser é autêntico, original.

Thatiana: [sermos] nós mesmos?

Marcelo: Isso! E eu acho que você tem pecado um pouco, sabe? É... até porque, eu acho que eu não te conheço, e você não se faz conhecer. ${ }^{8}$

\section{A discussão desencadeada pela intervenção} de Marcelo deixou Thatiana transtornada. Implicitamente, a inautenticidade da professora aludida pelo médico dizia respeito, em especial, a uma suposta homossexualidade não assumida de Thatiana. Diversas atitudes e comentários dela no confinamento levaram Marcelo, e muitos fãs da Net.BBB, a acreditar que a brasiliense escondia, não somente dos colegas, mas também de si mesmo, sua verdadeira orientação sexual. Para piorar, a capitulação da professora às investidas amorosas desferidas pelo seu companheiro de confinamento Marcos, começou a ser vista como uma simples estratégia de jogo, e não como reflexo de sentimentos verdadeiros. Já em seu quarto, depois do bate-boca com Marcelo, Thatiana confessou, aos prantos, que seus melhores amigos eram gays, que já havia beijado mulheres no passado e que gostava de frequentar a cena gay de Brasília (embora não tenha se descrito como homossexual).

Esse tipo de embate entre participantes, em que um deles tenta "tirar a máscara" do outro, ou seja, revelar perspectivas dos colegas que seriam - consciente, ou inconscientemente escondidas da audiência, é bastante popular na Net.BBB. A discussão acima, por exemplo, foi intensamente comentada em praticamente todos os blogs e no fórum. Naza, a administradora do blog Cabaré da Nazaré, publicou sete vídeos, com duração total de 65 minutos, contendo 0 entrevero completo, desde a intervenção inicial do médico, até as lamentações de Thatiana com Marcos e Rafinha em seu quarto. 0 primeiro desses vídeos disponibilizados por Naza obteve aproximadamente $100.000^{9}$ acessos no Youtube. E esse não foi um caso isolado, pelo contrário. Marcelo foi responsável por várias outras discussões que ganharam grande repercussão na

Diálogo ocorrido em 28 de fevereiro de 2008. 
Net.BBB. 0 vídeo, em que ele acusa a participante Thalita de manipular seus companheiros, obteve mais de 540.000 acessos. ${ }^{10}$ Já 0 desentendimento em que o médico aponta no carioca Fernando um comportando falso no programa foi responsável por $780.000^{11}$ visualizações, somente em um dos vários vídeos que mostrava a briga.

0 apoio recebido por Marcelo na Net.BBB era decorrente, em grande parte, de sua falta de atenção às regras de etiqueta nas interações face a face. Nas tentativas de desmascarar os colegas, o médico não fazia concessões; ele simplesmente os interpelava de maneira desafiadora, por vezes agressiva. Muitos fãs interpretavam essa não aderência a certas convenções sociais de polidez como sinal de autenticidade. Contudo, o uso excessivo (e, frequentemente, fora de contexto) desse adjetivo na comunidade fez com que alguns fãs começassem a questionar sua validade. Ao apoiar a crítica de Rê à banalização do conceito de autenticidade no Big Brother Brasil, Zé Mané também defende aqueles participantes do programa que criam personagens como estratégia de jogo, ou seja, não tentam ser autênticos:

\section{Rê e a tal autenticidade}

As pessoas adoraram banalizar o sentido de autenticidade [mensagem escrita por Rê]
Concordo contigo! Em outros BBBs o cliché mais usado era chamar os outros de "falso", desta vez a o lugar-comum do momento é "autenticidade". Até o famigerado Marcelo dizia como se tivesse descoberto a pólvora que "as pessoas na casa deveriam ser autênticas" (sic).

Eu me pergunto: por que as pessoas têm que ser autênticas? 0 que é ser autêntica? [mensagem escrita por Zé Mané] ${ }^{12}$

Embora o questionamento de Zé Mané acerca da sobrevalorização de uma suposta autenticidade dos participantes no Big Brother seja coerente, pode-se argumentar que seria difícil dissociar 0 reality show desse tipo de narrativa do indivíduo. Mesmo que esse conceito tenha sido usado em excesso no BBB8, conforme sugere 0 fã, o cotidiano criado dentro do confinamento é, fundamentalmente, estruturado de modo a maximizar a comunicação dessa característica. A pressão imposta por meio das provas de resistência e do isolamento do mundo externo, por exemplo, são percebidos como maneiras eficazes de se "quebrar as cascas" dos confinados, conforme propôs a comentarista Material Girl. De acordo com relatos expostos anteriormente, esses aspectos do formato teriam por objetivo vencer resistências psicológicas e emocionais dos participantes do BBB responsáveis pelo encobrimento de seus traços mais profundos. 
Entretanto, o cotidiano concebido para o programa tem outra função igualmente importante no que diz respeito à transmissão de uma ideia de autenticidade. As dificuldades enfrentadas pelos participantes do Big Brother Brasil funcionam como etapas a serem vencidas dentro de um processo de autoconhecimento. Para ultrapassar os obstáculos presentes no formato, o competidor do reality show deve mostrar capacidade de crescer e de se autorrealizar dentro do período de duração do BBB. 0 (auto) aprendizado com os erros e desafios encontrados seria, de acordo com essa moral, prova da existência de uma originalidade individual e de uma competência em manter ameaças externas sob controle.

Susan escreveu um post em que analisa a performance de Marcelo no BBB8. Na opinião da blogueira, o médico teve papel fundamental no reality show na medida em que realizou 0 desejo da audiência de buscar a autenticidade de seus colegas de confinamento. Porém, Marcelo cometeu um pecado que, possivelmente, teria sido responsável pela sua eliminação antecipada da competição: ele não foi capaz de incorporar as experiências e descobertas de sua vivência no Big Brother ao seu "eu". Susan coloca essa perspectiva do seguinte modo:

Marcelo foi em busca dessa verdade. Mas, esqueceu-se de, no processo, também viver as suas próprias descobertas. 0 maior aprendizado de todos é quando incorporamos essas experiências para olhar para dentro de nós. ${ }^{13}$

Rafinha, o vencedor do BBB8, por outro lado, parece ter compreendido bem o espírito da narrativa do crescimento interior e autorrealização. Na entrevista que deu em um chat do portal oficial do Big Brother Brasil na internet, logo após a final do programa, 0 roqueiro emo foi questionado por um fã sobre qual teria sido a maior lição que tirou do período em que ficou confinado. A resposta de Rafinha foi eloquente nesse aspecto: "A maior lição é ter aprendido a ouvir as pessoas e reconhecer os erros. Eu tinha rebeldia para aceitar determinadas situações". ${ }^{14}$ Algumas horas após a entrevista, a página oficial do reality show reforçou esse ponto no texto em que publicou comentando a vitória do roqueiro campinense:

Entre conquistas de amizades, garotas e prêmios, Rafinha fechou sua participação no BBB8 bem na fita: em suas participações na Máquina da Verdade, a tarja da mentira simplesmente não deu as caras e 0 brother reafirmou, durante toda a reta final do jogo, seu crescimento interno: 'Amadureci porque tinha uma situação que era uma falta de afinidade com Marcelo. Como eu já tive um problema parecido lá fora, resolvi não refletir meus erros aqui dentro'. (RAFINHA..., 2008)

Relatos como o do processo de aprendizado de Rafinha ao longo BBB8 expressam uma sintonia

Post publicado por Susan no blog De Cara Pra Lua ,<http://www.nabocadematildes.blogger.com.br/> em 11 de março de 2008. 
nos discursos, tanto da produção, quanto dos fãs do Big Brother Brasil, no que se refere a várias narrativas envolvendo a relação entre 0 indivíduo e a ideia de autenticidade. ${ }^{15}$

\section{Considerações finais}

As análises deste artigo buscaram decifrar algumas das implicações da crença compartilhada na Net.BBB - e, de certo modo, em uma parcela significativa da sociedade - de que todo indivíduo tem uma autenticidade própria que, no entanto, pode ser suprimida por "máscaras", adotadas com 0 intuito de lhes garantir alguma vantagem social. Tentou-se igualmente compreender 0 contexto cultural de nossa época responsável pela noção popularmente aceita de que não somente é necessário buscar essa autenticidade em nós mesmos e nos outros, mas também, de que quando certo indivíduo não oferece acesso ao seu eu autêntico, deve-se colocá-lo em situações de intensa pressão para que seja possível tirar as máscaras que cobrem a sua verdadeira face. 0 desejo dos fãs do BBB de assistir os confinados do programa serem submetidos a um ambiente de estresse não é nada mais do um reflexo de uma espécie de Zeitgeist da concepção do self contemporâneo. Não é coincidência, portanto, que 0 candidato ao prêmio máximo do Big Brother também deve encaixar-se na descrição que Beck (2001) e Giddens (1991) fazem do modelo do nosso tempo: 0 do sujeito que sabe se autoatualizar, evoluir e autoconstruir.

\section{Referências}

ANDREJEVIC, Mark. The kinder, gentler gaze of Big Brother: reality TV in the age of digital capitalism. New Media \& Society, v. 4, n. 2, p. 251-270, 2002.

BECK, Ulrich. World risk society. Oxford: Blackwell, 2001.

\section{CAMPANELLA, Bruno. Os olhos do grande} irmão: Uma etnografia dos fãs do Big Brother Brasil. Porto Alegre: Sulina, 2012.

ERIKSEN, Thomas Hylland. Small places, large issues: An introduction to social anthropology.

Londres: Pluto Press, 2001

\section{FREUD, Sigmund. Civilization and its}

discontents. Londres: Hogarth Press, 1963.

GIDDENS, Anthony. Modernity and self-identity. Stanford, CA: Stanford University Press, 1991. GOFFMAN, Erving. A representação do eu na vida cotidiana. Petrópolis, RJ: Vozes, 1983.

HELLER, Dana. Bailando ao redor do mundo: 0 apelo global dos reality shows de dança. In: Freire Filho, João (Ed.) A TV em transição: tendências de programação no Brasil e no mundo. Porto Alegre: Editora Sulina, 2009. p. 111-138.

LAING, Ronald. 0 eu dividido: estudo existencial da sanidade e da loucura. Petrópolis: Vozes, 1973.

MARCUSE, Herbert. Eros and civilization: a philosophical inquiry into Freud. Londres: Routledge, 2005.

RAFINHA é o vencedor do BBB 2008. 2008. Disponível em: < http://bbb.globo. 
com/BBB8/Noticias/0,,MUL363607-9451,00-

RAFINHA +E +0+VENCEDOR +D0+BBB.html $>$.

STAUB, Richard. Madness is Civilization: When the diagnosis was social: 1948-1980. Chicago:

University of Chicago Press, 2011.

TAYLOR, Charles. The ethics of authenticity.

Cambridge, MA: Harvard University Press, 1997.

TRILLING, Lionel. Sincerity and authenticity.

Cambridge, MA: Harvard University Press, 1972.

WINNICOTT, Donald. 0 ambiente e os processos

de maturação: estudos sobre a teoria do

desenvolvimento emocional. Porto Alegre: Editora

Artes Médicas Sul, 1988. 
Seizing the masks: Reality show and the search for authenticity in contemporary world

\section{Quitando las mascaras: \\ Lo reality show y la búsqueda por autenticidad en el mundo contemporáneo}

\section{Abstract}

This article aims to reflect upon the importance of authenticity as a concept for the audience of the Brazilian Big Brother (BBB). The results of a media ethnography of an online community of fans of the show suggest that the conditions created by the confinement inside the BBB house are ideal for the revealing of the housemates' authenticity. Key to this debate is the analyses carried out in the article of the romantic model of the "expressive self", still in vogue in the west. According to this model, every individual has her own authenticity, which it is assumed that can be supressed by the borrowing of "social masks". According to the BBB fans, however, some aspects of the housemates' confinement could have the effect of seizing those masks.

\section{Keywords}

Brazilian Big Brother. Subjectivity.

Confinement. Authenticity.

\section{Resumen}

Este artículo busca reflexionar al respecto de la importancia del concepto de autenticidad para la audiencia de la versión brasileña del programa Big Brother (BBB). Los resultados de la etnografía mediática de una comunidad online de fans del programa sugieren que las condiciones generadas por el confinamiento en la casa del BBB son las ideales para la revelación de la autenticidad de los participantes del reality show. El tema clave de la reflexión presentada en este trabajo tiene como su referencia esencial el análisis del modelo romántico de "self expresivo", todavía en boga en el occidente. Según este paradigma, los individuos poseen una autenticidad propia que, se supone, puede ser suprimida por "máscaras sociales" adoptadas. Sin embargo, para los fans del BBB, algunas matices del confinamiento podrían ser capaces de obligar que los participantes del programa quitasen dichas máscaras.

\section{Palabras-clave}

Big Brother Brasil. Subjetividad.

Confinamiento. Autenticidad. 


\section{Expediente}

A revista E-Compós é a publicação científica em formato eletrônico da Associação Nacional dos Programas de Pós-Graduação em Comunicação (Compós). Lançada em 2004, tem como principal finalidade difundir a produção acadêmica de pesquisadores da área de Comunicação, inseridos em instituições do Brasil e do exterior.
E-COMPÓS I www.e-compos.org.br I E-ISSN 1808-2599

Revista da Associação Nacional dos Programas

de Pós-Graduação em Comunicação.

E-compós, Brasilia, v.16, n.1, jan./abr. 2013

A identificação das edições, a partir de 2008,

passa a ser volume anual com três números.

\section{CONSELHO EDITORIAL}

Afonso Albuquerque, Universidade Federal Fluminense, Brasil Alberto Carlos Augusto Klein, Universidade Estadual de Londrina, Brasil Álvaro Larangeira, Universidade Tuiuti do Paraná, Brasil André Luiz Martins Lemos, Universidade Federal da Bahia, Brasil Ângela Freire Prysthon, Universidade Federal de Pernambuco, Brasil Angela Cristina Salgueiro Marques, Faculdade Cásper Líbero (São Paulo), Brasil Antonio Roberto Chiachiri Filho, Faculdade Cásper Líbero, Brasil Arthur Autran Franco de Sá Neto, Universidade Federal de São Carlos, Brasil Benjamim Picado, Universidade Federal Fluminense, Brasil César Geraldo Guimarães, Universidade Federal de Minas Gerais, Brasil Cristiane Freitas Gutfreind, Pontifícia Universidade Católica do Rio Grande do Sul, Brasil

Denilson Lopes, Universidade Federal do Rio de Janeiro, Brasil Eduardo Peñuela Cañizal, Universidade Paulista, Brasil

Eduardo Vicente, Universidade de São Paulo, Brasil Eneus Trindade, Universidade de São Paulo, Brasil Erick Felinto de Oliveira, Universidade do Estado do Rio de Janeiro, Brasil Florence Dravet, Universidade Católica de Brasília, Brasil Gelson Santana, Universidade Anhembi/Morumbi, Brasil Gislene da Silva, Universidade Federal de Santa Catarina, Brasil Guillermo Orozco Gómez, Universidad de Guadalajara Gustavo Daudt Fischer, Universidade do Vale do Rio dos Sinos, Brasil Hector Ospina, Universidad de Manizales, Colômbia Herom Vargas, Universidade Municipal de São Caetano do Sul, Brasil Inês Vitorino, Universidade Federal do Ceará, Brasil Jay David Bolter, Georgia Institute of Technology Jeder Silveira Janotti Junior, Universidade Federal de Pernambuco, Brasil John DH Downing, University of Texas at Austin, Estados Unidos José Afonso da Silva Junior, Universidade Federal de Pernambuco, Brasil José Carlos Rodrigues, Pontifícia Universidade Católica do Rio de Janeiro, Brasil José Luiz Aidar Prado, Pontifícia Universidade Católica de São Paulo, Brasil Kelly Cristina de Souza Prudêncio, Universidade Federal do Paraná, Brasil.
Laan Mendes Barros, Universidade Metodista de São Paulo, Brasil Lance Strate, Fordham University, USA, Estados Unidos Lorraine Leu, University of Bristol, Grã-Bretanha Lucia Leão, Pontifícia Universidade Católica de São Paulo, Brasil Malena Segura Contrera, Universidade Paulista, Brasil

Márcio de Vasconcellos Serelle, Pontifícia Universidade Católica de Minas Gerais, Brasil

Maria Aparecida Baccega, Universidade de São Paulo e Escola Superior de Propaganda e Marketing, Brasil

Maria Ataide Malcher, Universidade Federal do Pará, Brasil

Maria das Graças Pinto Coelho, Universidade Federal do Rio Grande do Norte, Brasil Maria Immacolata Vassallo de Lopes, Universidade de São Paulo, Brasil Maria Luiza Martins de Mendonça, Universidade Federal de Goiás, Brasil Mauro de Souza Ventura, Universidade Estadual Paulista, Brasil Mauro Pereira Porto, Tulane University, Estados Unidos Mirna Feitoza Pereira, Universidade Federal do Amazonas, Brasil Nilda Aparecida Jacks, Universidade Federal do Rio Grande do Sul, Brasil Osvando J. de Morais, Universidade de Sorocaba, Brasil Potiguara Mendes Silveira Jr, Universidade Federal de Juiz de Fora, Brasil Renato Cordeiro Gomes, Pontifícia Universidade Católica do Rio de Janeiro, Brasil Robert K Logan, University of Toronto, Canadá

Ronaldo George Helal, Universidade do Estado do Rio de Janeiro, Brasil Rose Melo Rocha, Escola Superior de Propaganda e Marketing, Brasil Rossana Reguillo, Instituto de Estudos Superiores do Ocidente, Mexico Rousiley Celi Moreira Maia, Universidade Federal de Minas Gerais, Brasil Sebastião Guilherme Albano da Costa, Universidade Federal do Rio Grande do Norte, Brasil

Simone Maria Andrade Pereira de Sá, Universidade Federal Fluminense, Brasil Tiago Quiroga Fausto Neto, Universidade de Brasília, Brasil Suzete Venturelli, Universidade de Brasília, Brasil Valerio Fuenzalida Fernández, Puc-Chile, Chile

Veneza Mayora Ronsini, Universidade Federal de Santa Maria, Brasil Vera Regina Veiga França, Universidade Federal de Minas Gerais, Brasil

\section{COMISSÃO EDITORIAL}

Adriana Braga I Pontifícia Universidade Católica do Rio de Janeiro, Brasil

Felipe Costa Trotta I Universidade Federal Fluminense, Brasil

CONSULTORES AD HOC

Bruno Campanella, Universidade Federal Fluminense, Brasil

Christa Berger, Universidade do Vale do Rio dos Sinos, Brasil

Edison Gastaldo, Universidade Federal Rural do Rio de Janeiro, Brasil

José Luiz Braga, Universidade do Vale do Rio dos Sinos, Brasil

\section{EDIÇÃO DE TEXTO E RESUMOS I Susane Barros}

SECRETÁRIA EXECUTIVA I Juliana Depiné

EDITORACã̃ ELETRÔNICA I Roka Estúdio
COMPóS I www.compos.org.br

Associação Nacional dos Programas de Pós-Graduação em Comunicação

Presidente

Julio Pinto

Pontifícia Universidade Católica de Minas Gerais, Brasil juliopinto@pucminas.br

Vice-presidente

Itania Maria Mota Gomes

Universidade Federal da Bahia, Brasil

itania@ufba.br

Secretária-Geral

Inês Vitorino

Universidade Federal do Ceará, Brasil

inesvic@gmail.com 